\title{
Knockdown of hnRNP A2/B1 inhibits cell proliferation, invasion and cell cycle triggering apoptosis in cervical cancer via PI3K/AKT signaling pathway
}

\author{
XIANG SHI ${ }^{1,2}$, LI RAN $^{3}$, YAO LIU ${ }^{1,2}$, SHU-HUAI ZHONG ${ }^{1,2}$, \\ PING-PING ZHOU ${ }^{1,2}$, MING-XIN LIAO ${ }^{1,2}$ and WEN FANG ${ }^{1}$
}

\begin{abstract}
${ }^{1}$ Department of Biochemistry, The Affiliated Hospital of Guizhou Medical University; ${ }^{2}$ Department of Clinical Biochemistry, Guizhou Medical University; ${ }^{3}$ Department of Mammary Gland and Gynecologic Oncology, Guizhou Cancer Hospital, Department of Oncology, The Affiliated Hospital of Guizhou Medical University, Guiyang, Guizhou 550004, P.R. China
\end{abstract}

Received August 12,2017; Accepted December 29, 2017

DOI: $10.3892 /$ or.2018.6195

\begin{abstract}
Cervical cancer is currently one of the major threats to women's health. The overexpression of heterogeneous nuclear ribonucleoprotein A2/B1 (hnRNP A2/B1) as the biomarker has been investigated in various cancers. In our previous study, we found that lobaplatin induced apoptosis and cell cycle arrest via downregulation of proteins including hnRNP A2/B1 in cervical cancer cells. However, the underlying relationship between hnRNP A2/B1 and cervical cancer remained largely unknown. hnRNP A2/B1 knock-down in HeLa and CaSki cells was performed by shRNA transfection. The expression of hnRNP A2/B1 was detected by western blot and Quantitative Real-time PCR. Cell proliferation, migration, invasion and the $\mathrm{IC}_{50}$ of lobaplatin and irinotecan were determined by MTT assay, Transwell assay, Plate colony formation assay and wound healing assay. Flow cytometry was perfomed to investigate cell apoptosis and the cell cycle. The expression of PI3K, AKT, p-AKT, p21, p27, caspase-3, cleaved caspase-3 were revealed by western blot. Nude mouse xenograft model
\end{abstract}

Correspondence to: Professor Wen Fang, Department of Biochemistry, The Affiliated Hospital of Guizhou Medical University, 28 Guiyi Street, Guiyang, Guizhou 550004, P.R. China E-mail: fangwen@gmc.edu.cn

Abbreviations: hnRNP A2/B1, heterogeneous nuclear ribonucleoprotein A2/B1; qRT-PCR, quantitative reverse transcription polymerase chain reaction; shRNA, short hairpin RNA; RPMI-1640, Roswell Park Memorial Institute-1640; MTT, 3-(4,5-dimethylthiazol-2-yl)-2,5-diphenyl tetrazolium bromide; PBS, Phosphate buffere saline; $\mathrm{IC}_{50}$, half maximal inhibitory concentration; DMSO, dimethylsulphoxide; SDS, Sodium dodecyl sulfate; PI3K/AKT, phophatidylinositol 3-kinase/protein kinase-B; CDK, cyclin dependent kinase; IGF-1, insulin-like growth factor 1; PCNA, proliferating cell nuclear antigen; H\&E, hematoxylin and eosin; DAB, 3,3'-diaminobenzidine; IOD, integrated option density

Key words: cervical cancer, hnRNP A2/B1, proliferation, apoptosis, PI3K/AKT was undertaken with HeLa cells and the xenograft tumor tissue samples were analyzed for the expression of PCNA and Ki-67 by immunohistochemistry and the cell morphology was evaluated by hematoxylin and eosin (H\&E). Results revealed that hnRNP A2/B1 was successfully silenced in HeLa and CaSki cells. hnRNP A2/B1 knock-down significantly induced the suppression of proliferation, migration, invasion and also enhancement of apoptosis and reduced the $\mathrm{IC}_{50}$ of lobaplatin and irinotecan. The expression of p21, p27 and cleaved caspase-3 in shRNA group were significantly upregulated and the expression of $\mathrm{p}-\mathrm{AKT}$ was reduced both in vitro and in vivo. The results of immunohistochemistry showed that PCNA and Ki-67 were significantly downregulated in vivo. The growth of nude mouse xenograft tumor was significantly reduced by hnRNP A2/B1 knock-down. Taken together, these data indicate that inhibition of hnRNP A2/B1 in cervical cancer cells can inhibit cell proliferation and invasion, induce cell-cycle arrestment and trigger apoptosis via PI3K/AKT signaling pathway. In addition, after silencing hnRNP A2/B1 can increase the sensitivity of cervical cancer cells to lobaplatin and irinotecan.

\section{Introduction}

Cervical cancer is one of the most severe malignant tumors and it also has high rates of morbidity especially in many developing countries (1). China's National Cancer Center earlier published data showed that the incidence and mortality rate of cervical cancer is $10.4 / 10^{5}$ and $2.59 / 10^{5}$ (2). Contemporary management of cervical cancer involves chemotherapy, surgery and radiotherapy (3). As recommended by the National Comprehensive Cancer Network (NCCN), Platinum-based chemotherapy is often used in cervical cancer management (4). However, common platinum-based drugs, for example, cisplatin, often induce resistance. Thus there is an urgent need of novel drugs for cervical cancer management (5).

The heterogeneous nuclear ribonucleoprotein (hnRNP) family consists of approximately $20 \mathrm{hnRNA}$-binding proteins and most of them are related to key biogenesis of messenger RNA (mRNA) (6). The hnRNP A2/B1 complex are important 
members of hnRNP family and are made up of the proper proportion of protein $\mathrm{A}$ and protein $\mathrm{B}$, it has been proved that hnRNPs regulate transportation and splicing of mRNA in cells $(7,8)$. Several studies have demonstrated that hnRNP A2/B1 was highly expressed in gastric adenocarcinoma, pancreatic cancer and glioblastoma. Overexpression of hnRNP A2/B1 in non-small cell lung cancer increased cell proliferation, while downregulation of hnRNP A2/B1 enhanced apoptosis of breast cancer cells. Importantly, hnRNP A2/B1 has been used as biomarker and prognostic indicator in non-small cell lung cancer (9-13). However, the role of hnRNP A2/B1 in cervical cancer has not been fully studied.

Phophatidylinositol3-kinase/protein kinase-B (PI3K/AKT) signaling pathway and its downstream targets play important roles in tumorigenesis. For example, PI3K/AKT pathway trigger tumor cell death through binding to $\mathrm{Bad} / \mathrm{Bcl}-2$ complex and inactive caspase-8/9 $(14,15)$. Moreover, the PI3K/AKT signaling pathway is involved in cell proliferation by activating cyclin dependent kinase (CDK), upregulating cyclins and downregulating p21/Waf1/Cip1 and p27/Kip2 (16). A study based on the Cancer Genome Atlas revealed that the expression of the subunits of PI3K/AKT varies in cervical cancer, ovarian cancer and uterine epithelial tumor (17). However the relationship between hnRNP A2/B1 and PI3K/AKT in cervical cancer has not been fully clarified.

From previous research, we found that hnRNP A2/B1 was inhibited in CaSki cells after treatment with lobaplatin (18). However the relationship between hnRNP A2/B1 and $\mathrm{PI} 3 \mathrm{~K} / \mathrm{AKT}$ in cervical cancer is not clear and the underlying mechanism remains unknown. Thus, in this study, we explored the role of hnRNP A2/B1 in proliferation, apoptosis as well as relationship between hnRNP A2/B1 and PI3K/AKT pathway in cervical cancer both in vitro and in vivo.

\section{Materials and methods}

Cell culture. Human cervical cancer cells HeLa and CaSki were purchased from the cell bank of the Type Culture Collection of Chinese Academy of Sciences (Shanghai, China). Cells were cultured in RPMI-1640 medium (Hyclone, Logan, UT, USA) supplemented with $10 \%$ fetal bovine serum (Gibco, Grand Island, NY, USA), 1\% penicillin-streptomycin (Solarbio, Beijing, China) and 1\% L-glutamine (Amresco, Solon, $\mathrm{OH}, \mathrm{USA}$ ) in a $5 \% \mathrm{CO}_{2}$ incubator at $37^{\circ} \mathrm{C}$. The medium was replaced every 2-3 days, and subsequent studies were performed when cells in exponential growth phase.

hnRNP A2/B1-shRNA design and cell transfection. pGMLV-SC5 RNAi lentiviral vector (Fig. 1) was purchased from Genomeditech (Shanghai, China). We followed the criteria described by Invitrogen (Carlsbad, CA, USA) to design multiple shRNAs targeting hnRNP A2/B1 or negative control mRNA sequence. Four of the positive targeting sequences and one negative shRNA against hnRNP A2/B1 sequence (Table I) were specially chosen for subsequent studies. Synthesized oligonucleotides (Table II) were annealed and ligated to the $B a m \mathrm{HI} / E c o$ RI sites of pGMLV-eGFP to produce pGMLV-eGFP-shhnRNP A2/B1 or pGMLV-eGFP-shCon, eGFP expression was used to exhibit the infection of lentiviruses. The HeLa and CaSki cells were cultured in RPMI-1640
Table I. Four specific target sequences of hnRNPA2/B1 gene.

\begin{tabular}{lc}
\hline No. & \multicolumn{1}{c}{ TargetSeq } \\
\hline 1 & CAGAAATACCATACCATCAAT \\
2 & TGACAACTATGGAGGAGGAAA \\
3 & GGGCTCATGTAACTGTGAAGA \\
4 & GCTTTGTCTAGACAAGAAATG \\
NC-shRNA & TTCTCCGAACGTGTCACGT \\
\hline
\end{tabular}

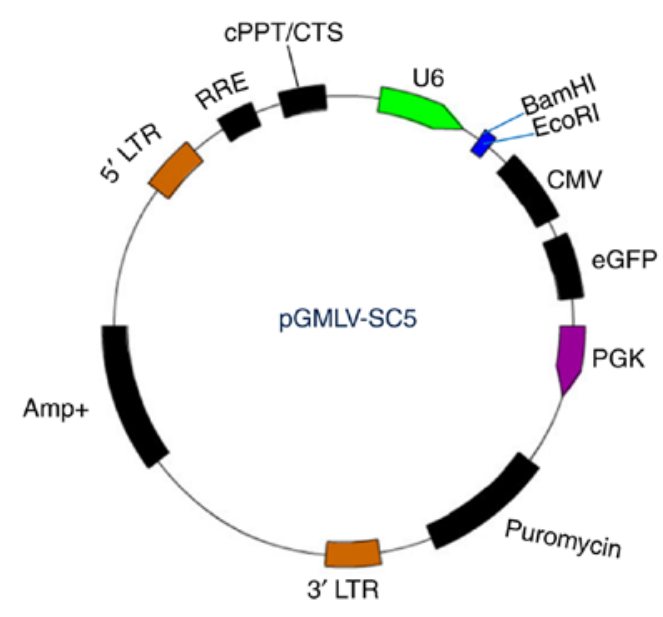

Figure 1. Map of pGMLV-SC5 RNAi lentiviral vector.

supplemented with $10 \%$ FBS, $1 \%$ penicillin-streptomycin liquid and $1 \% \mathrm{~L}$-glutamine at 6-well plate. When the cells were in exponential growth phase, the medium of the negative control of HeLa or CaSki cells were replaced by medium with NC-shRNA diluent and the positive group were replaced by medium with hnRNP A2/B1-shRNA diluent. After $24 \mathrm{~h}$, the culture media was replaced with RPMI-1640 medium, and cells were incubated in an incubator for $72 \mathrm{~h}$. HeLa and CaSki were further screened in media consisting of puromycin $(2 \mathrm{mg} / \mathrm{l})$. Because pGMLV-SC5RNAi lentiviral vector contains eGFP and anti-puromycin gene, the cells transfacted with lentiviral vector can reveal green fluorescence. Then the eGFP-positive cells can be picked up for further analysis.

Quantitative real-time PCR analysis. HeLa and CaSki cells were transfected with either control or hnRNP A2/B1 shRNAs as described previously, total RNA was extracted by trizol (Invitrogen), cDNAs were synthesized from total RNAs by SuperScript VILO cDNA Synthesis kit (Invitrogen) according to the manufacturer's protocol. Quantitative real-time PCR was performed by SYBR-Green PCR Master Mix (Applied Biosystems, USA). The specific primers for cDNA were as follows: hnRNP A2/B1, sence: 5'-GATGGCAGAGAACGG TGTGAAG-3', and antisense, 5'-AGGCATAGGTATTGGCAA CTGC-3'. $\beta$-actin, sence: 5'-GTCTCCTCTGACTTCAACAGC G-3', antisence: 5'-ACCACCCTGTTGCTGTAGCCAA-3'. $\beta$-actin was considered as an internal control. PCR reaction conditions were perfomed as follows: $95^{\circ} \mathrm{C}$ for $10 \mathrm{~min}$, and $40 \mathrm{cycles}$ of $95^{\circ} \mathrm{C}$ for $15 \mathrm{sec}$ and $60^{\circ} \mathrm{C}$ for $60 \mathrm{sec}$. The respective gene expression were calculated by the $2^{-\Delta \Delta C \mathrm{Ct}}$ method. 
Table II. Oligos of 4 pairs of shRNA and 1 pair of NC-shRNA.

Oligo Oligonucleotide DNA sequence 5' to $3^{\prime}$

3935hnRNPA2/B1-shRNA1-T (EcoRI)

3935hnRNPA2/B1-shRNA1-B (BamHI)

3936hnRNPA2/B1-shRNA2-T (EcoRI)

3936hnRNPA2/B1-shRNA2-B (BamHI)

3937hnRNPA2/B1-shRNA3-T (EcoRI)

3937hnRNPA2/B1-shRNA3-B (BamHI)

3938hnRNPA2/B1-shRNA4-T (EcoRI)

3938hnRNPA2/B1-shRNA4-B (BamHI)

NC-shRNA1-1

NC-shRNA1-2

gatccGCAGAAATACCATACCATCAATCTCGAGATT
GATGGTATGGTATTTCTGTTTTTg
aattcAAAAAACAGAAATACCATACCATCAATCTCGAGA
TTGATGGTATGGTATTTCTGCg
gatccGTGACAACTATGGAGGAGGAAACTCGAGTTT
CCTCCTCCATAGTTGTCATTTTTg
aattcAAAAAATGACAACTATGGAGGAGGAAACTCG
AGTTTCCTCCTCCATAGTTGTCACg
gatccGGGCTCATGTAACTGTGAAGACTCGAGTCTTCA
CAGTTACATGAGCCCTTTTTTg
aattcAAAAAAGGGCTCATGTAACTGTGAAGACTCGAG
TCTTCACAGTTACATGAGCCCg
gatccGCTTTGTCTAGACAAGAAATGCTCGAGCATTT
CTTGTCTAGACAAAGCTTTTTTg
aattcAAAAAAGCTTTGTCTAGACAAGAAATGCTCGAG
CATTTCTTGTCTAGACAAAGCg
gatccGTTCTCCGAACGTGTCACGTTTCAAGAGAACGT
GACACGTTCGGAGAACTTTTTACGCGTg
aattcACGCGTAAAAAAGTTCTCCGAACGTGTCAC
GTTCTCTTGAAACGTGACACGTTCGGAGAACg

gatccGCAGAAATACCATACCATCAATCTCGAGATT GATGGTATGGTATTTCTGTTTTTTg aattcAAAAAACAGAAATACCATACCATCAATCTCGAGA TTGATGGTATGGTATTTCTGCg gatccGTGACAACTATGGAGGAGGAAACTCGAGTTT CCTCCTCCATAGTTGTCATTTTTTg aattcAAAAAATGACAACTATGGAGGAGGAAACTCG AGTTTCCTCCTCCATAGTTGTCACg gatccGGGCTCATGTAACTGTGAAGACTCGAGTCTTCA CAGTTACATGAGCCCTTTTTTg TCTTCACAGTTACATGAGCCCg CTTGTCTAGACAAAGCTTTTTTg aattcAAAAAAGCTTTGTCTAGACAAGAAATGCTCGAG CATTTCTTGTCTAGACAAAGCg gatccGTTCTCCGAACGTGTCACGTTTCAAGAGAACGT aattcACGCGTAAAAAAGTTCTCCGAACGTGTCAC GTTCTCTTGAAACGTGACACGTTCGGAGAACg

Western blot analysis. HeLa and CaSki cells and nude mouse tumor tissues were lysed by RIPA lysis buffer containing $1 \%$ PMSF and $1 \%$ protein phosphatase inhibitor for $30 \mathrm{~min}$ and then centrifuged at $14,000 \times \mathrm{g}$ at $4^{\circ} \mathrm{C}$ for $20 \mathrm{~min}$. Collecting the supernatant to store at $-80^{\circ} \mathrm{C}$. The protein concentration was performed by Bradford assay kit. Cells and tissue lysates were electrophoresed by SDS-PAGE and proteins were transferred to PVDF membrane (Millipore) and then blocked with Tris-buffered saline Tween-20 with 5\% non-fat milk for $2 \mathrm{~h}$. Next, they were incubated with primary antibodies diluted with TBST overnight at $4^{\circ} \mathrm{C}$, the primary antibodies were as follows: Anti-hnRNP A2/B1 (Bioworld Technology, St. Louis Park, MN, USA; 1:1,000), anti-AKT (Proteintech, Wuhan, China; 1:500), anti-p-AKT (Cell Signaling Technology, Danvers, MA, USA; 1:1,000), anti-p21 (Abcam, Cambridge, UK; 1:2,000), anti-p27 (Abcam; 1:1,000), anti-PI3K (Wanleibio, Shenyang, China; 1:500), anti-caspase-3 (Wanleibio; 1:500), anti-cleaved caspase-3 (Wanleibio; 1:500), $\beta$-actin (Bioss, Beijing, China; 1:6,000) was used as a loading control and followed by incubation with secondary antibody (ZSGB-Bio, Beijing, China; 1:90,000) at room temperature for $1 \mathrm{~h}$. Chemiluminent detection was determined by ECL kit. ImageJ software was used to conclude data.

Cell proliferation assay. HeLa and CaSki with hnRNP A2/B1-shRNA, NC-shRNA and control group cells were digested by $0.25 \%$ trypsin (Gibco), diluted to $5 \times 10^{4} / \mathrm{ml}$ and the single cell was suspended in $200 \mu \mathrm{l}$ culture medium and then seeded in 96-well plates to culture in a $5 \% \mathrm{CO}_{2}$ incubator at $37^{\circ} \mathrm{C}$ overnight. Subsequently, the medium was respectively replaced by $200 \mu \mathrm{l}$ of new medium that consisted of insulin-like growth factor 1 (IGF-1, Prospec-Tany Technogene
Ltd., Rehovot, Israel) and LY294002 (Beyotime Biotechnology Corporation, Shanghai, China) or not for $12,24,48 \mathrm{~h}$. The concentration of IGF-1 on HeLa and CaSki cells was $100 \mathrm{ng} / \mathrm{ml}$, the concentration of LY294002 on HeLa and CaSki cells was 20 and $15 \mu \mathrm{M}$, respectively. Then the culture medium was removed before the 3-(4,5-dimethylthiazol-2-yl)-2,5-diphenyl tetrazolium bromide (MTT) solution $(5 \mathrm{mg} / \mathrm{ml})$ was added to the medium and maintained at $37^{\circ} \mathrm{C}$ for $4 \mathrm{~h}$, the supernatant was removed and $150 \mu \mathrm{l}$ DMSO was added to each well under the absorbance measurement at $490 \mathrm{~nm}$.

Colony formation assay. Single-cell suspensions were digested with $0.25 \%$ trypsin, harvested and seeded into 6-well plates for 500 cells per well and then cultured in RPMI-1640 in a $5 \% \mathrm{CO}_{2}$ incubator at $37^{\circ} \mathrm{C}$ for two weeks. The cell supernatants were removed and washed twice with PBS after visible colonies appeared. Cells were cultured with $4 \%$ paraformaldehyde for $15 \mathrm{~min}$ then stained with moderate gentian violet solution for $30 \mathrm{~min}$ before being washed with PBS. The efficiency of the assay was estimated as follows: Clone forming efficiency $=$ number of colonies/number of inoculated cells $\mathrm{x} 100 \%$.

Cell invasion assay. The invasion of HeLa and CaSki cells was estimated by transwell chambers. Serum free medium and matrigel (1:4) solution $\left(60 \mu \mathrm{l}\right.$ of $\left.4^{\circ} \mathrm{C}\right)$ was added to upper chambers for $4-5 \mathrm{~h}$ at $37^{\circ} \mathrm{C}$. The $200 \mu \mathrm{l}$ single-cell suspensions $\left(2 \times 10^{5} / \mathrm{ml}\right)$ were seeded into upper chamber and the lower chambers were fixed with $10 \%$ medium to incubate for $24 \mathrm{~h}$. The chamber which was fixed in $100 \%$ methanol was taken out and subsequently stained with $2 \%$ crystal violet for 
$30 \mathrm{~min}$. The cell invasion assay was performed by the stained cells in the chamber.

Wound healing assay. Single-cell suspensions were diluted to $5 \times 10^{5}$ per well and seeded into 6 -well plates subsequently cultured with serum-free medium overnight. Then the adherent cells were washed with PBS 3 times and exposed in different drugs, respectively, for 0 and $24 \mathrm{~h}$ after the cells were scratched by $10 \mu 1$ pipette tip across the center of the well. The gap distance was photographed by microscopy. ImageJ was used to assess quantitative data.

Cell cycle assay. The exponential phase of HeLa and CaSki cells were added with $0.25 \%$ trypsin for digestion, collected, centrifuged at $100 \mathrm{x} \mathrm{g}$ at $4^{\circ} \mathrm{C}$ for $5 \mathrm{~min}$. Cells were fixed with $70 \%$ ethanol after supernatant was removed and then suspended in $50 \mu \mathrm{g} / \mathrm{ml}$ RNaseA (KeyGen Biotech Corp., Ltd., Jiangsu, China) at $37^{\circ} \mathrm{C}$ for $30 \mathrm{~min}$ and stained in $50 \mu \mathrm{g} / \mathrm{ml}$ PI (KeyGen Biotech Corp., Ltd.) solution for $30 \mathrm{~min}$ in the dark. The single-cell suspensions were performed by flow cytometry.

Cell apoptosis assay. Cells in the exponential phase were digested and diluted to a $5 \times 10^{4} / \mathrm{ml}$ suspension and seeded into 6-well plates overnight. Subsequently, $5 \times 10^{5}$ single-cell suspension was collected with $500 \mu$ l Binding Buffer, then fixed with $5 \mu$ l Annexin APC (KeyGen Biotech Corp., Ltd.) and $5 \mu \mathrm{l}$ PI (KeyGen Biotech Corp., Ltd.) staining solution in the dark for $15 \mathrm{~min}$. Apoptosis of different cells were evaluated by flow cytometry.

IC ${ }_{50}$ of HeL a and CaSki by MTT assay. Cells $\left(5 \times 10^{4} / \mathrm{ml}\right)$ were harvested and seeded in 96-well plates, exposed in different concentrations of lobaplatin or irinotecan (concentration was determined by pre-experimentation and referenced to the data of published (18-20), final concentration: $2,4,6,8,12$ and $16 \mu \mathrm{g} / \mathrm{ml}$ or $20,40,60,80,160$ and $240 \mu \mathrm{g} / \mathrm{ml}$, Hainan Changan International Pharmaceutical Co., Ltd., Hainan, China) in a $5 \% \mathrm{CO}_{2}$ incubator at $37^{\circ} \mathrm{C}$ for $24 \mathrm{~h}$, the test wells were six-replica. Then each well was fixed with $10 \mu \mathrm{l}$ per well 3-(4,5-dimethylthiazol-2-yl)-2,5-diphenyl tetrazolium bromide (MTT) (final concentration: $5 \mu \mathrm{g} / \mathrm{ml}$ ) for $4 \mathrm{~h}$. Subsequently, the media was removed and $150 \mu \mathrm{l}$ per well of DMSO was added before it was measured at $490 \mathrm{~nm}$ by an enzyme standard instrument. This was repeated three times and the average value was taken.

Tumor xenograft experiment. Female BALB/c nude mice at 4 weeks were purchased from Chongqing National Bio Industrial Base Experimental Animal Center (Chongqing, China). HeLa cells $\left(2 \times 10^{6} / \mathrm{ml}\right)$ were collected and suspended in $200 \mu$ l PBS. The cell suspensions were injected subcutaneously into the right side near the back of the neck, all of the nude mice were kept in a homeothermic and specific pathogen-free room, temperature and humidity were maintained at $26-28^{\circ} \mathrm{C}$ and $40-60 \%$. Nude mice were randomly divided into 3 groups (7 mice per group), Vernier caliper was performed to measure tumor volume every 3 days. All the nude mice were sacrificed by breaking the neck after anesthetized by $10 \%$ chloral hydrate and tumor tissues were collected for the next analysis after 30 days. The tumor volume calculation method referred to the following formula: $\left(\mathrm{LxW}^{2}\right) / 2(21)$, where $\mathrm{L}$ is the longest tumor diameter and $\mathrm{W}$ is the shortest tumor diameter. Animal experiments were strictly as the guidelines of Guizhou Medical University Animal Care Welfare Committee (number: 1702256).

Immunohistochemistry. The expression of PCNA and Ki-67 in nude mice injected with HeLa cells were revealed by immunohistochemistry assay. Fresh tissues were soaked in $4 \%$ neutral formaldehyde for $24 \mathrm{~h}$ and then dehydrated and paraffin-embedded, the adhesion slides with 4- $\mu$ m sections were kept at $60^{\circ} \mathrm{C}$ for $4 \mathrm{~h}$. Deparaffinizing with xylene and hydrating with an ethanol gradient. Followed by citrate buffer under high pressure to repair the antigen for $3 \mathrm{~min}$ and then the slides were incubated with $0.3 \% \mathrm{H}_{2} \mathrm{O}_{2}$ for $30 \mathrm{~min}$. After that, the sections were rinsed by PBS-T (PBS with 1\% Tween-20) and were blocked with $10 \%$ goat serum for $30 \mathrm{~min}$ at $37^{\circ} \mathrm{C}$. Subsequently, the sections were treated with rabbit polyclonal anti-PCNA (Bioss; 1:100) and rabbit polyclonal anti-Ki-67 (Bioss; $1: 100$ ) at $4^{\circ} \mathrm{C}$ overnight. According to the recommendation of the antibody specification, positive tissue sections of PCNA (rat liver) and Ki-67 (mouse placenta tissue) were used as control, with PBS instead of primary antibody treated as a negative control. After successfully completing the previous steps, the sections were incubated with a secondary antibody for $20 \mathrm{~min}$ at $37^{\circ} \mathrm{C}$ and then 3,3'-diaminobenzidine (DAB) color reagent was added followed by hematoxylin staining. The slides were dehydrated and then mounted in neutral resins. Image acquisition was performed by microscope and Image-Pro Plus 6.0 software was used to analyze the Integrated Option Density (IOD) values of the brown area and then the IOD values of each group were statistically analyzed.

$H \& E$ staining. The pretreatment of hematoxylin and eosin (H\&E) staining was basically the same as the immunohistochemical steps. Sections $(4 \mu \mathrm{m})$ were treated with hematoxylin reagent for $5 \mathrm{~min}$ after deparaffinization and rehydration and then treated with $1 \%$ acid-ethanol for $1 \mathrm{sec}$. Subsequently, the sections were stained by eosin reagent for $3 \mathrm{~min}$. The slides were dehydrated and mounted then photographed by microscopy.

Statistical analysis. The data was collected and expressed as means \pm SD. SPSS.23.0 software was used for statistical analysis. All of the experiment were repeated three times and the average value was taken. The comparison of the means of two groups was analyzed by Student's t-test. For all of the differences, $\mathrm{P}<0.05$ was considered to indicate a statistically significant difference.

\section{Results}

hnRNP A2/B1 is significantly downregulated by lentivirusmediated shRNA in HeLa and CaSki cells. qRT-PCR and western blot were used to evaluate the efficiency of hnRNP A2/B1 knockdown by lentivirus-mediated shRNA. The results showed that the expression of hnRNP A2/B1 was highly suppressed at both mRNA and protein levels. We designed 4 hnRNP A2/B1-shRNA, the results of qRT-PCR indicted that the best inhibition efficiency was HeLa-shRNA4 


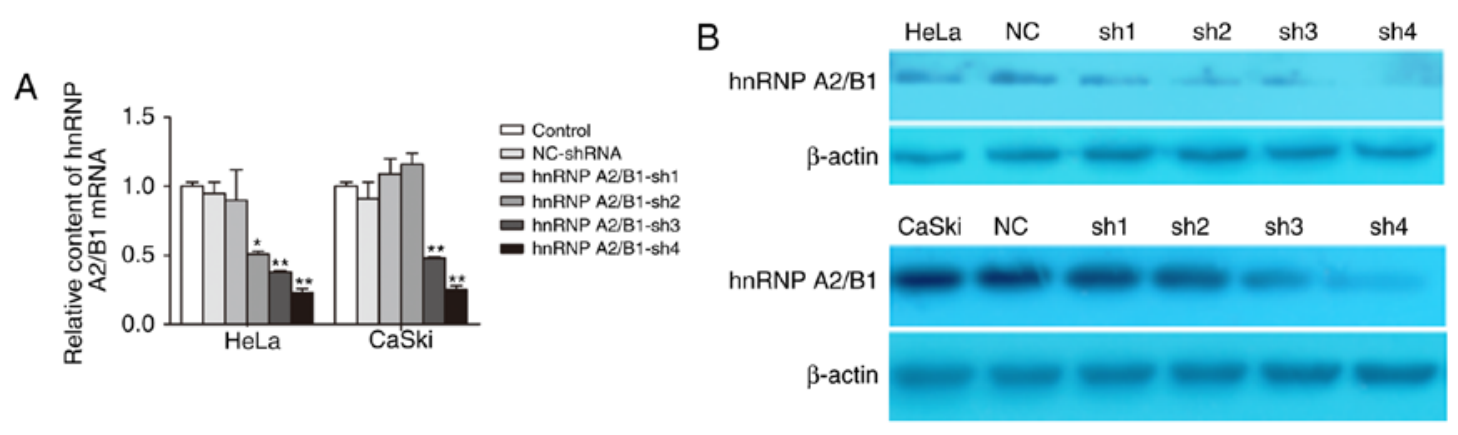

Figure 2. Inhibition of hnRNP A2/B1 by Lentivirus mediated shRNA in HeLa and CaSki cells. (A) The mRNA expression levels of hnRNP A2/B1 in each group were measured by qRT-PCR assay. (B) Western blot was used to evaluate the protein expression in each downregulation group, control and NC group in HeLa and CaSki cells ( $\left({ }^{*} \mathrm{P}<0.05 ;{ }^{* *} \mathrm{P}<0.01\right)$.
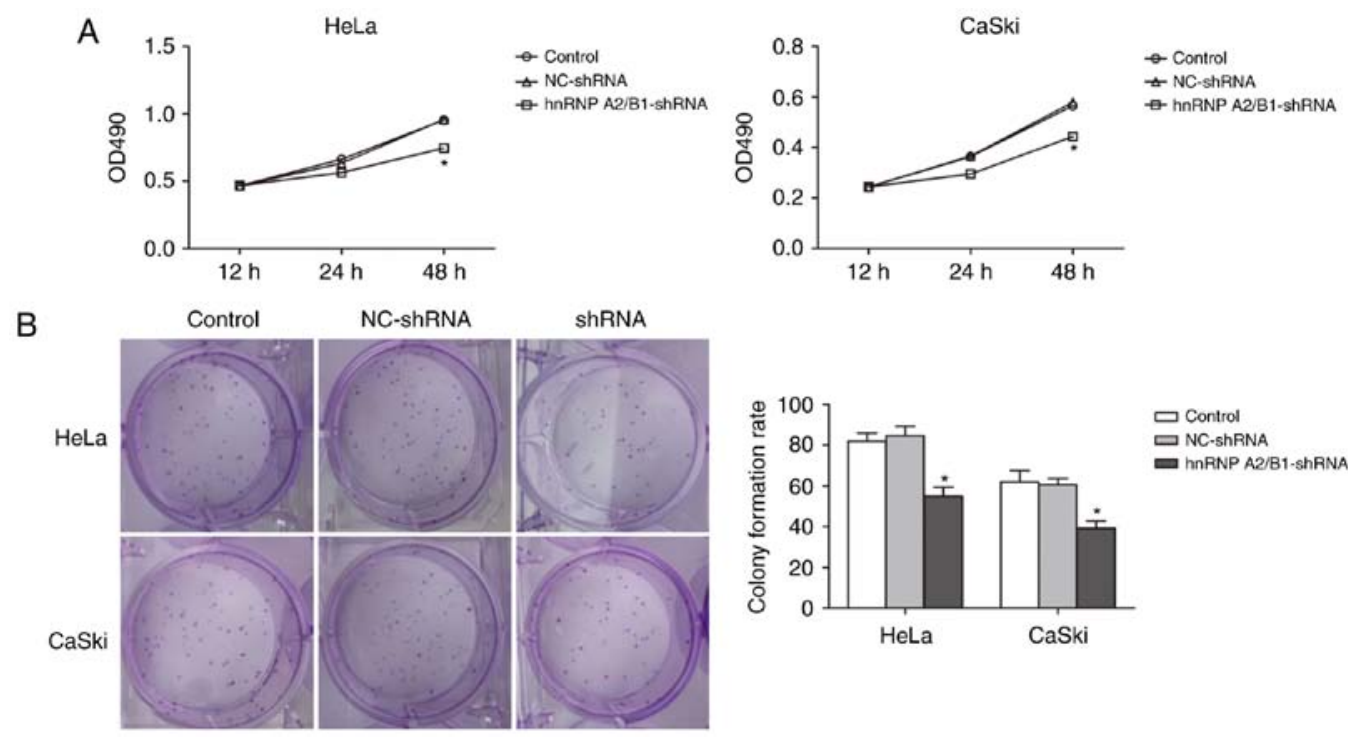

Figure 3. Knockdown of hnRNP A2/B1 impaires cervical cancer cell line proliferation and colony formation efficiency in vitro. (A) The MTT assay was used to demonstrate proliferation in hnRNP A2/B1 knockdown cells after incubated for 12, 24 and $48 \mathrm{~h}$, the suppression of hnRNP A2/B1 inhibited the proliferation in HeLa and CaSki cells. (B) The ability of colony formation was decreased in both cervical cancer cell lines after hnRNP A2/B1 silencing. The experiment was repeated three times independently and all data are presented as means $\pm \mathrm{SD}\left({ }^{*} \mathrm{P}<0.05\right)$.

(76.58 $\pm 3.55 \%)$ and CaSki-shRNA4 (74.79 $\pm 3.38 \%)$ (Fig. 2A). Western blot showed that protein expression of hnRNP A2/B1 in HeLa-shRNA4 (73.25 $\pm 2.78 \%)$ and CaSki-shRNA4 $(85.74 \pm 6.52 \%)$ was markedly decreased compared to levels in other shRNA and NC-shRNA group (Fig. 2B). These results confirmed that the hnRNP A2/B1 was significantly knoced down in HeLa and CaSki cells which were used for further experiments.

Inhibition of proliferation and colony formation in cervical cancer cells via hnRNP A2/BI knockdown. MTT assay was used to demonstrate the relationship between suppression of hnRNP A2/B1 and cell proliferation (Fig. 3A). Absorbance value was measured in HeLa and CaSki cells at 12, 24 and $48 \mathrm{~h}$. The absorbance value of hnRNP A2/B1-shRNA in HeLa and CaSki cells significantly decreased compared with NC-shRNA and blank control group at $48 \mathrm{~h}$ suggesting successful inhibition of cell proliferation in hnRNP A2/B1 knockdown cell lines.

In addition, colony formation efficiency was decreased in both hnRNP A2/B1 shRNA-treated HeLa and CaSki cell lines, as shown by the colony formation assay (Fig. 3B). An at least 30\% drop in the colony formation rate was observed in HeLa hnRNP A2/B1-shRNA cells as compared to HeLa blank control or HeLa NC-shRNA cells $(55.00 \pm 4.35$ vs. $82.00 \pm 4.00$ or $84.67 \pm 4.61)$. The colony formation rate was also decreased by more than 35\% in CaSki hnRNP A2/B1-shRNA cells as compared to CaSki blank control or CaSki NC-shRNA cells $(39.33 \pm 3.50$ vs. $62.00 \pm 5.57$ or $60.67 \pm 3.05)$. No significant difference between NC-shRNA and blank control group was observed.

Inhibition of migration and invasion in HeLa and CaSki cells after hnRNP A2/B1 knockdown. The migration defect mediated by knockdown hnRNP A2/B1 in HeLa and CaSki cells were performed by wound-healing assay (Fig. 4A and C). Cell motility potential in hnRNP A2/B1-shRNA in HeLa and CaSki cells was significantly decreased compared with NC-shRNA and blank control group. For HeLa cells, the relative migration rate of hnRNA A2/B1-shRNA cells was $431.33 \pm 20.03$ as compared to $702.00 \pm 7.21$ or $707.33 \pm 7.57$ of blank control or NC-shRNA cells. For CaSki cells, the relative migration rate 


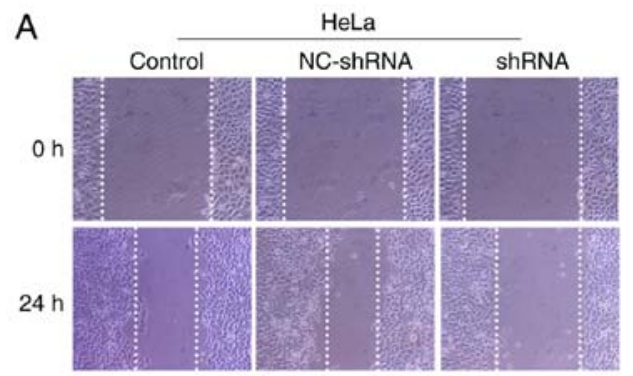

B

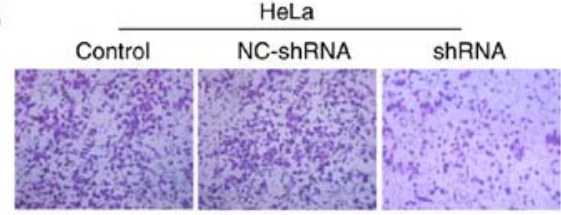

C

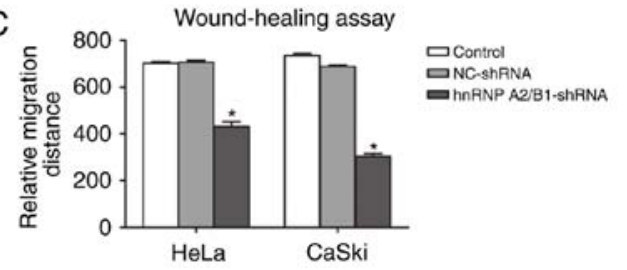

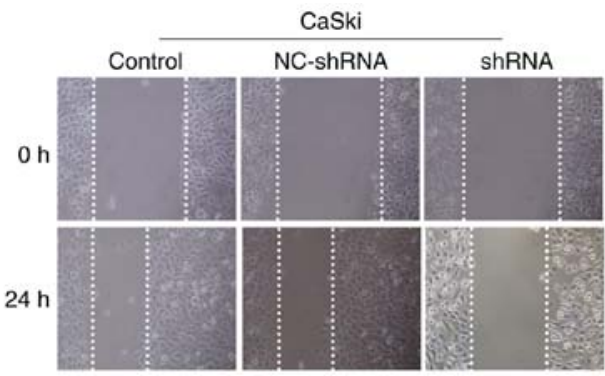
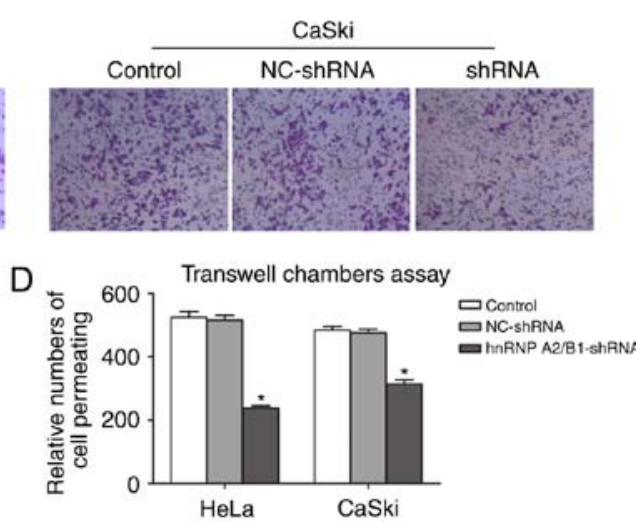

Figure 4. The ability of migration and invasion in HeLa and CaSki cells compared between hnRNP A2/B1-shRNA group and other two groups. (A and C) After incubated for $24 \mathrm{~h}$, wound-healing assay was used to show the ability of migration between each group in HeLa and CaSki cells. (B and D) Transwell analysis of the invasion of hnRNP A2/B1 shRNA-transfected with both HeLa and CaSki cells as described in (B and D). The data was collected and expressed as means $\pm \mathrm{SD}\left({ }^{*} \mathrm{P}<0.05\right)$.

was halved in hnRNA A2/B1 knockdown cells as compared to blank control or NC-shRNA group $(303.33 \pm 12.22$ vs. $735.33 \pm 8.33$ or $688.00 \pm 6.00$ ).

Transwell chamber assay was used to exhibit invasion ability (Fig. 4B and D). In both cell lines, the number of cell permeating in hnRNA A2/B1 knockdown cells dropped significantly from blank control or NC-shRNA cells $(237.67 \pm 7.51$ vs. $524.67 \pm 17.5$ or $515.33 \pm 15.01$ in HeLa cells; $313.67 \pm 13.05$ vs. $483.67 \pm 10.97$ or $476.00 \pm 11.00$ in CaSki cells) and again we did not observe a significant difference between blank control and NC-shRNA groups for either cell line.

The enhancement of chemotherapy sensitivity of lobaplatin or irinotecan by suppression of hnRNP A2/B1 in HeLa and CaSki cells. The $\mathrm{IC}_{50}$ value of lobaplatin or irinotecan in $\mathrm{HeLa}$ and CaSki cells was detected by MTT assay. The $\mathrm{IC}_{50}$ of lobaplatin in HeLa blank control, HeLa NC-shRNA and HeLa hnRNPA2/B1-shRNA was 7.526 $\pm 0.17,7.816 \pm 0.19$, $4.669 \pm 0.03 \mu \mathrm{g} / \mathrm{ml}$, respectively. The $\mathrm{IC}_{50}$ value of blank control group, $\mathrm{NC}$ group, shRNA group was $11.340 \pm 0.49,12.240 \pm 0.20$ and $7.677 \pm 0.34 \mu \mathrm{g} / \mathrm{ml}$ in lobaplatin treated CaSki cells. The $\mathrm{IC}_{50}$ of irinotecan in HeLa blank control group and HeLa NC-shRNA group were $78.487 \pm 1.69$ and $76.277 \pm 1.09 \mu \mathrm{g} / \mathrm{ml}$, CaSki blank control group and CaSki NC-shRNA group was $94.250 \pm 3.05$ and $110.233 \pm 6.38 \mu \mathrm{g} / \mathrm{ml}$, but the hnRNP A2/B1-shRNA group of HeLa and CaSki cells were decreased significantly to $55.447 \pm 0.224$ and $63.593 \pm 2.76 \mu \mathrm{g} / \mathrm{ml}$. The $\mathrm{IC}_{50}$ value of lobaplatin and irinotecan in HeLa and CaSki cells had no statistical significance between NC-shRNA group and blank control group (Fig. 5A-F). The results indicate that inhibition of hnRNP A2/B1 boosts the sensitivity of cervical cancer lines towards lobaplatin and irinotecan.
PI3K/AKT signaling pathway plays an important role in hnRNP A2/BI-regulated cell cycle and apoptosis in cervical cancer cell lines. Flow cytometry was used to investigate the effect of hnRNP A2/B1 knockdown on cell cycle distribution in HeLa and CaSki cells. The proportion of G1 phase cells in hnRNP A2/B1 knockdown HeLa and CaSki cells was significantly increased (Fig. 6A and Table III). No significant difference was seen between NC-shRNA group and blank control group in HeLa or CaSki cells.

We also looked into the relationship between hnRNP A2/B1 inhibition and cell apoptosis. In both HeLa and CaSki cell lines, the apoptosis rate was increased after hnRNP knockdown as compared to blank control or NC groups (25.53 vs. $11.83 \%$ or $14.01 \%$ in HeLa cells; 46.20 vs. $12.40 \%$ or 11.97 in CaSki cells); (Fig. 6B). The apoptosis rate was similar in the two control groups for both cell lines.

We further tested the change of PI3K/AKT pathway related proteins by Western blot in hnRNP A2/B1 knockdown cervical cancer cells (Fig. 6C). The hnRNP A2/B1 knockdown group showed the upregulation of p21, p27 and cleaved caspase-3 and downregulation of $\mathrm{p}-\mathrm{AKT}(\mathrm{P}<0.05)$. However, there is no obvious change in the expression level of PI3K and AKT in the knock-down cell lines.

Effects of hnRNPA2/B1 knockdown cells treated with IGF-1 and LY294002, respectively, or not on the activation or inhibition of PI3K/AKT pathway. To further illustrate the relationship between hnRNP A2/B1 and PI3K/AKT pathway, IGF-1 and LY294002 were used as agonist and inhibitor of the PI3K/AKT pathway. MTT assay and wound healing assay were used to investigate the proliferation and migration of HeLa and CaSki cells after incubated with IGF-1 and 
A

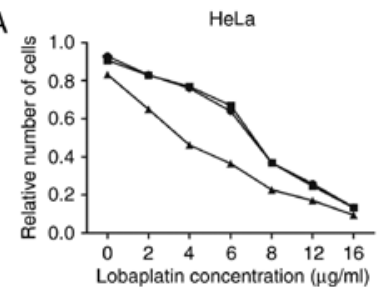

C
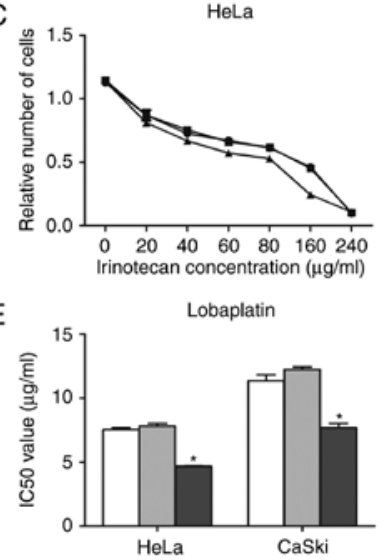

- Control

- hnRNP A2/B1-shRNA

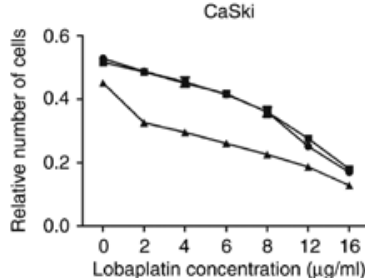

CaSki

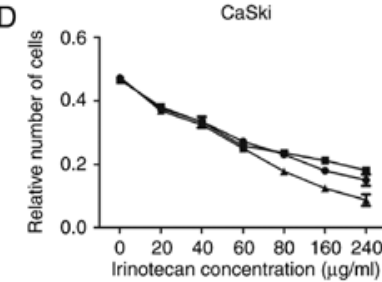

- NC-shRNA
- InRNP A2/B1-ShRNA

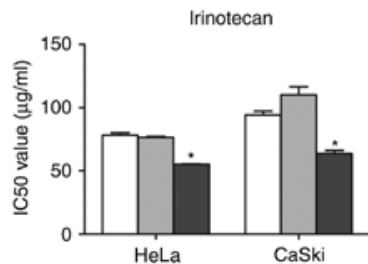

F
- Control

- NC-shPNA

- Control

- hIRNP A28B1-ShPNA

Control

口 NC-shRNA
InRNP A2/B1-ShPNA

Figure 5. The $\mathrm{IC}_{50}$ value of Lobaplatin and Irinotecan in HeLa and CaSki cervical cancer cells is decreased after hnRNP A2/B1-shRNA transfection. (A and B) The absorbance value of HeLa and CaSki cells incubated in different concentrations of Lobaplatin for $24 \mathrm{~h}$ was measured by MTT assay. (C and D) The absorbance value of both cell lines after treatment with Irinotecan for $24 \mathrm{~h}$ was shown by MTT assay. (E) The $\mathrm{IC}_{50}$ change of each group in HeLa and CaSki cells treatment with Lobaplatin for $24 \mathrm{~h}$. $(\mathrm{F}) \mathrm{The} \mathrm{IC}_{50}$ value comparison of each group after chemotherapy with irinotecan for $24 \mathrm{~h}$. These data was collected and expressed as means $\pm \mathrm{SD}\left({ }^{*} \mathrm{P}<0.05\right)$.

A

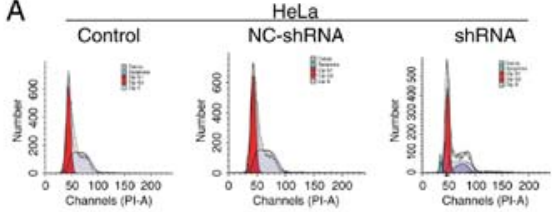

B
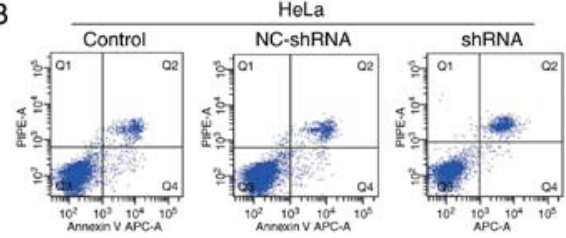

C

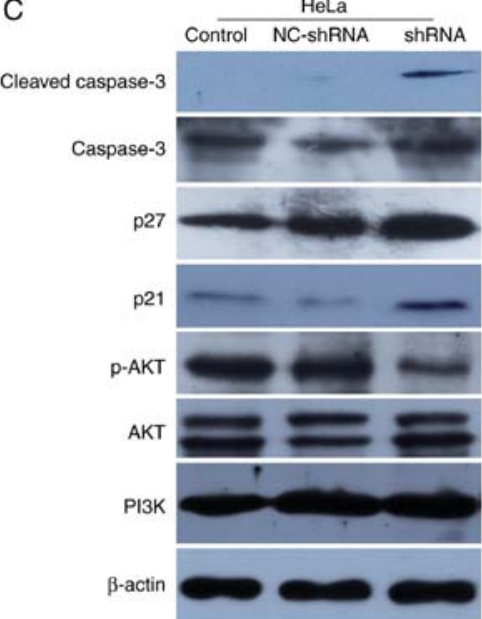

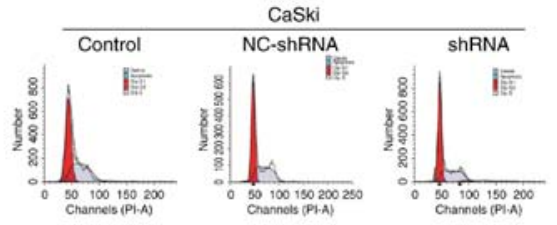
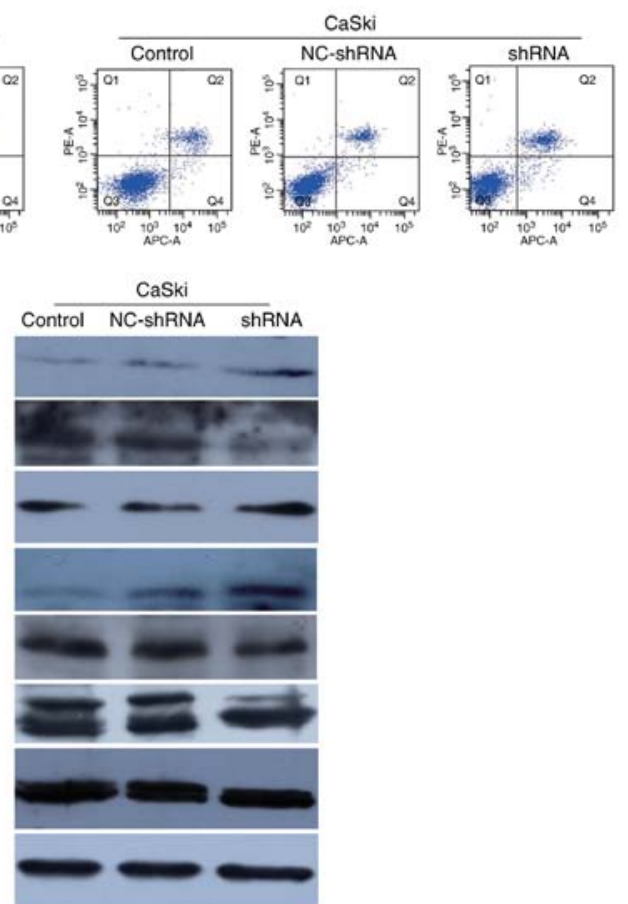

Figure 6. hnRNP A2/B1 inhibition induces G1/S cell cycle arrest and enhances cell apoptosis, regulates the expression of PI3K/AKT pathway related proteins after hnRNP A2/B1 knockdown in HeLa and CaSki cells. (A) The cell cycle was investigated by flow cytometry, the proportion of hnRNP A2/B1-shRNA transfection group in HeLa and CaSki cells at G1 phase was significantly increased compared to other groups. (B) Cell apoptosis of HeLa and CaSki cells were suggested by flow cytometry. Apoptosis was significantly increased in hnRNP A2/B1 knockdown group. (C) Western blot assay indicated that hnRNP A2/B1 knockdown resulted in upregulated expression of p21, p27 and cleaved caspase-3 and decreased p-AKT in HeLa and CaSki cells. 

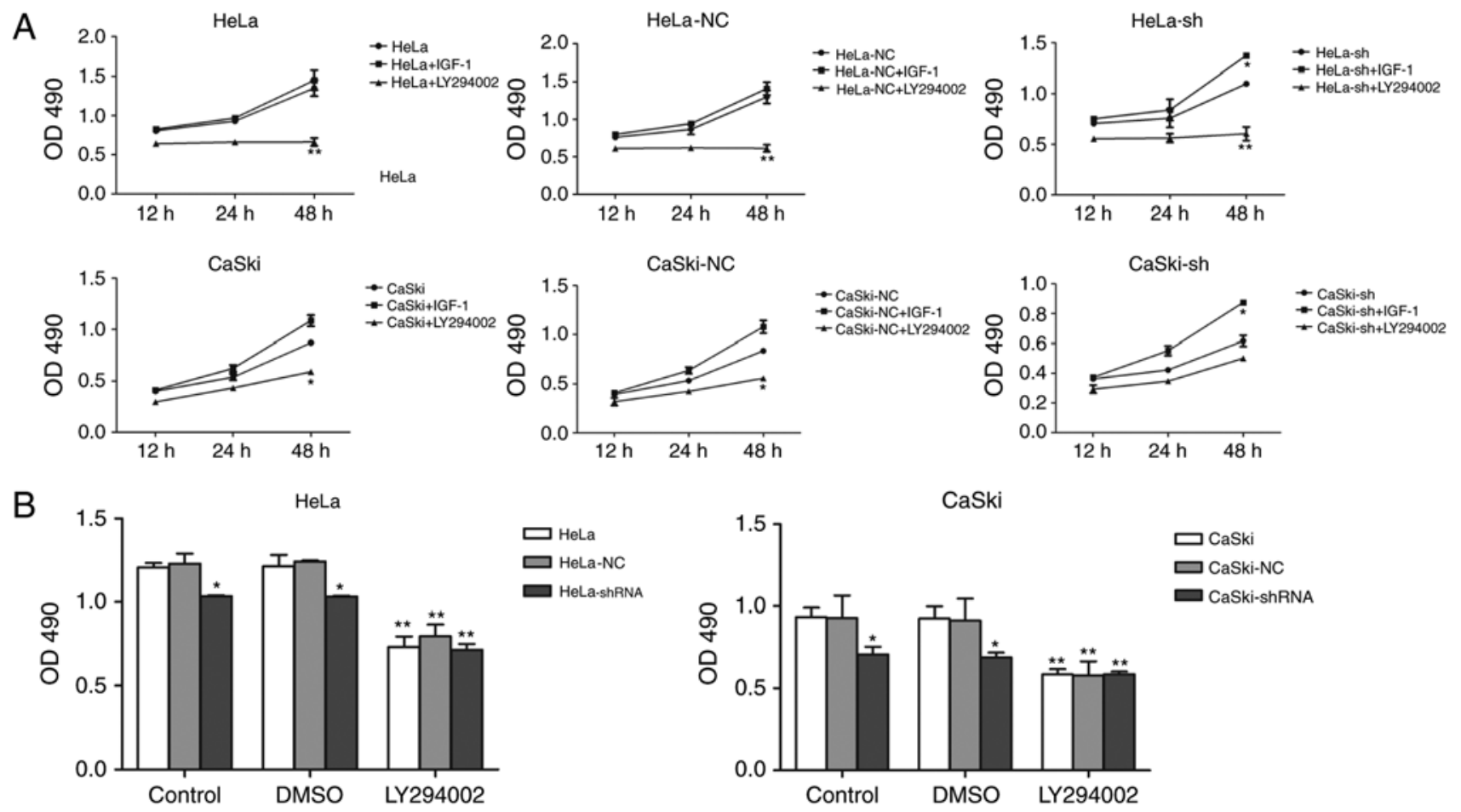

Figure 7. Partial rescue after the allocation of IGF-1 and LY294002 in HeLa and CaSki cells. (A) The proliferation of hnRNP A2/B1 knockdown was upregulated after using IGF-1 and downregulated after cultured with LY294002. (B) The proliferation of group of vehicle solution DMSO had no significant difference compared to the non-medicated group. The data are presented as means $\pm \mathrm{SD}$. ( $\left.\mathrm{P}<0.05 ;{ }^{* *} \mathrm{P}<0.01\right)$.

LY294002 (Figs. 7A and 8A). The proliferation and migration phenotype of hnRNP A2/B1 knockdown groups were rescued by IGF-1 treatment while worsened in LY294002 treated group. Validation of activation or inhibition of PI3K/AKT pathway after exposed to IGF-1 or LY294002 was performed by western blotting (Fig. 8B). The expression of p-AKT was significantly reduced after cultured in LY294002, while the expression of p-AKT was increased both in HeLa and CaSki cells after exposed in IGF-1 $(\mathrm{P}<0.01)$. The PI3K inhibitor LY294002 was dissolved in DMSO solution, so the same amount of DMSO was added into cells as the vehicle control group to avoid interference with the experiment. The PI3K activator IGF-1 was reconstituted in sterile 18M Omega-cm $\mathrm{H}_{2} \mathrm{O}$ according to instruction and so no vehicle control group in this drug. The proliferation of HeLa and CaSki cells at $48 \mathrm{~h}$ after cultured with DMSO was investigated by MTT assay (Fig. 7B), the DMSO group had no significant change compared to the non-medicated group.

Effect of hnRNPA2/B1 silencing on nude mouse xenograft in vivo. To determine the effect of hnRNP A2/B1 knockdown in vivo, the transfected HeLa cells were injected into nude mice to establish a tumor xenograft model. The nude mice were randomly divied into 3 groups for injection with HeLa, HeLa-NC shRNA and HeLa-hnRNP A2/B1 shRNA, respectively. Since a nude mouse of $\mathrm{NC}$ group was dead before inoculating tumor cells, the survival rate of nude mice injected with tumor cells was $100 \%$ and behavior was normal throughout the experiment. The results showed that the incidence of tumorigenesis in hnRNP A2/B1-shRNA transfected HeLa cells injected group was significantly lower compared to the control and NC-shRNA group (Fig. 9A and B). To demonstrate whether the proliferation
Table III. The influence of hnRNPA2/B1 on the cell cycle $(\mathrm{n}=3, \bar{x} \pm \mathrm{s})$.

\begin{tabular}{lcc}
\hline Group & $\mathrm{G}(\%)$ & $\mathrm{S}(\%)$ \\
\hline CaSki & $57.56 \pm 0.75$ & $42.52 \pm 0.22$ \\
CaSki-shRNA & $60.57 \pm 0.14^{\mathrm{a}}$ & $38.35 \pm 0.36$ \\
CaSki-NC & $57.36 \pm 0.55$ & $42.53 \pm 0.16$ \\
HeLa & $50.58 \pm 0.23$ & $49.44 \pm 0.21$ \\
HeLa-shRNA & $57.23 \pm 0.23^{\mathrm{a}}$ & $41.63 \pm 0.56$ \\
HeLa-NC & $51.21 \pm 0.17$ & $48.66 \pm 0.31$ \\
\hline
\end{tabular}

$\left({ }^{\mathrm{a}} \mathrm{P}<0.01\right)$.

capacity was consistent with the previous experiment results in vitro, immunohistochemistry was used to confirm the expression of PCNA and Ki-67 in vivo and the brown particles were labeled as positive areas. In addition, H\&E staining was used to observe the morphological structure in tumor tissues. The results suggested that the positive expression of PCNA $(\mathrm{P}<0.05)$ and Ki-67 $(\mathrm{P}<0.01)$ were significantly lower in hnRNP A2/B1 knockdown tumor group compared to the other group (Fig. 9C and Table IV). As shown in Fig. 9D, the characteristics of xenograft tissues conformed to tumor cells and were as follows: Acidophil hepatocytes with both nuclear and cytoplasmic enlargement, nuclear pleomorphism and hyperchromasia, and frequent multinucleation. In order to further demonstrate the relationship between the PI3K/AKT signaling pathway and hnRNP A2/B1 in nude mouse xenograft tissues, western blot- 

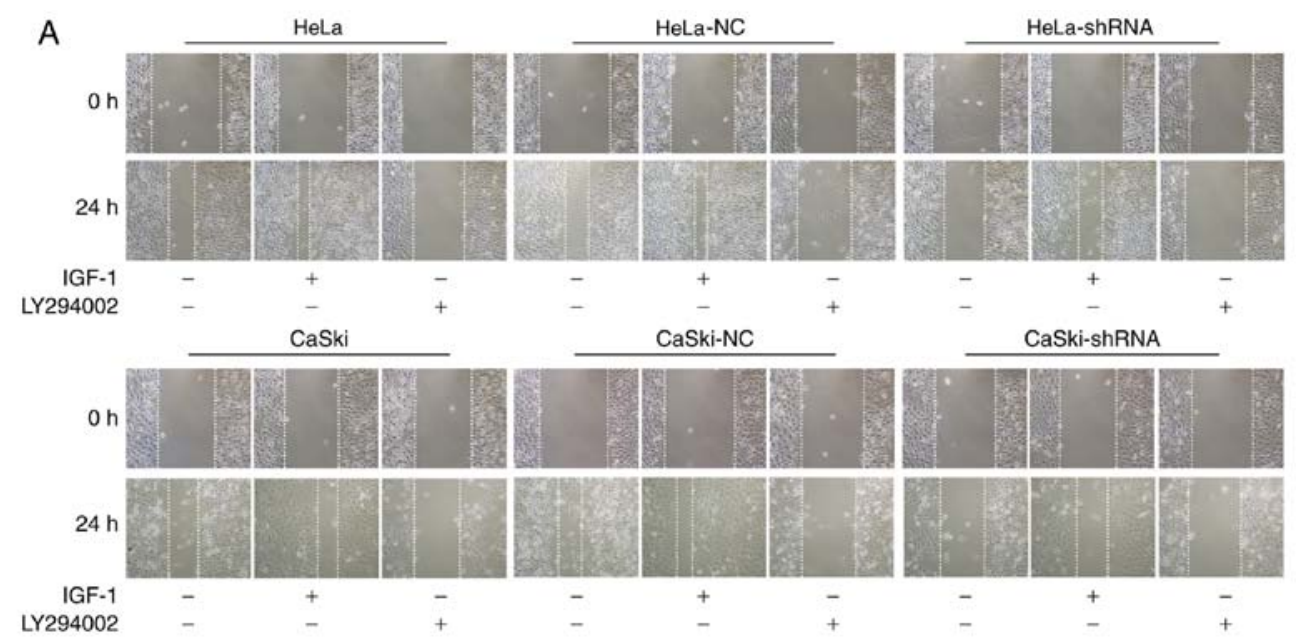

B

HeLa
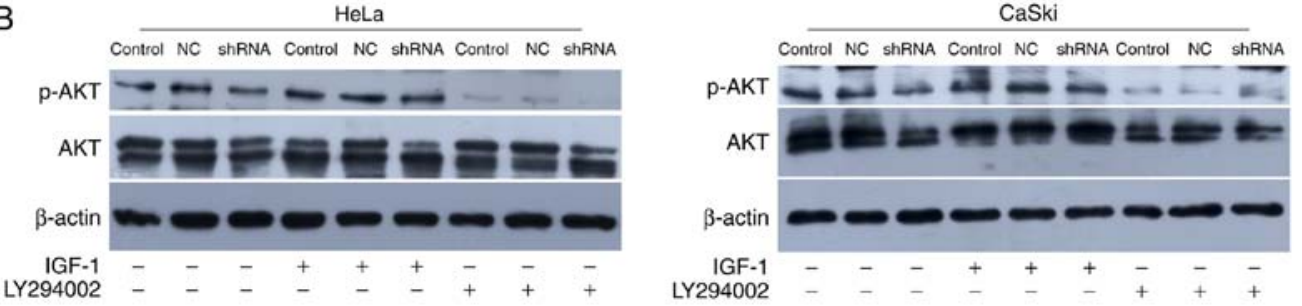

Figure 8. Partial effects after cultured with IGF-1 and LY294002. (A) The migration ability was inhibited by LY294002 and promoted by IGF-1. (B) Western blot exposed that activation of PI3K/AKT pathway was significantly increased by using IGF-1 and supression of PI3K/AKT pathway when LY294002 was added.

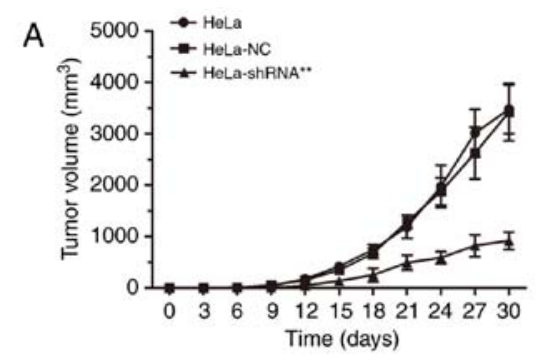

C

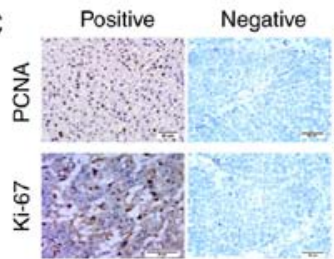

D

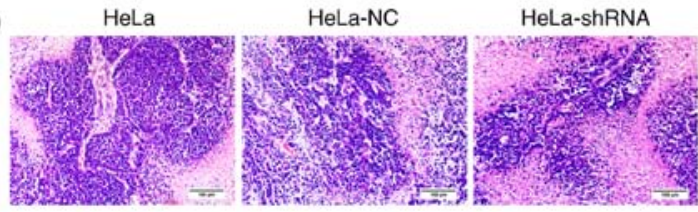

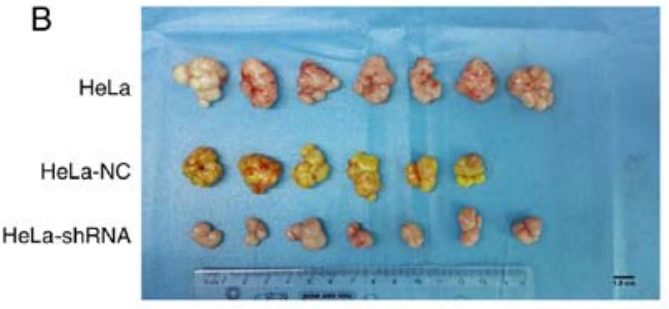

E Cleaved caspase-3

Caspase-3

p27

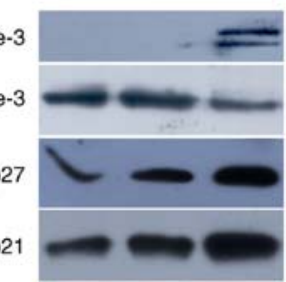

p21

p-AKT

AKT

PI3K

$\beta$-actin

$1+2+1=$

KT

K

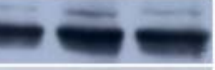

-

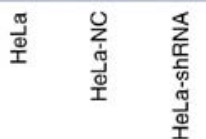

Figure 9. hnRNP A2/B1 knockdown inhibits the growth of cervical cancer HeLa cells in vivo. (A and B) Tumor growth of HeLa-hnRNPA2/B1-shRNA group was significantly suppressed compared to the control and NC-shRNA group. $(\mathrm{C})(400 \mathrm{x})$ The PCNA $(\mathrm{P}<0.05)$ and Ki-67 $(\mathrm{P}<0.01)$ proteins were used to indicate the expression of antigens associated with proliferation by immunohistochemistry, representative immunohistochemistry images showed both of then were downregulated in shRNA group. (D) (200x) hematoxylin and eosin (H\&E) staining showed that the nucleus were deeply stained and irregular, the proportion of the nucleus and cytoplasm was imbalanced. (E) The expression of PI3K/AKT signal pathway related proteins in xenograft tissues were performed by western blot, as shown in the representative image, p-AKT and caspase-3 proteins were downregulated in shRNA group, on the contrary, the expression of p21, p27 and cleaved caspase- 3 were increased significantly $\left({ }^{* *} \mathrm{P}<0.01\right)$. 
Table IV. The IOD values of PCNA and Ki-67 ( $\bar{x} \pm$ s).

\begin{tabular}{lrc}
\hline Group & PCNA & Ki-67 \\
\hline HeLa & $163256.50 \pm 38370.00$ & $43485.35 \pm 26291.10$ \\
HeLa-NC & $151597.80 \pm 33089.76$ & $43102.09 \pm 12737.12$ \\
HeLa-shRNA & $75461.77 \pm 22288.53^{\text {a }}$ & $13669.97 \pm 4926.23^{\text {b }}$ \\
\hline
\end{tabular}

$\left({ }^{\mathrm{a}} \mathrm{P}<0.05 ;{ }^{\mathrm{b}} \mathrm{P}<0.01\right)$.

ting was used for clarification. The xenograft tumor of hnRNP A2/B1-shRNA group could suppress the expression of p-AKT protein, upregulating cleaved caspase-3, p21 and p27 (Fig. 9E). The results indicated that it was consistent with the earlier apoptotic and cycle results in vitro from the protein level of xenograft tumor tissues.

\section{Discussion}

hnRNP A2/B1 is a set of primer-mRNA binding proteins involved in cell transcription and protein translation. Previous studies suggested that uncontrolled expression of hnRNP $\mathrm{A} 2 / \mathrm{B} 1$ is one of the reasons for promoting tumor formation and thus highly expressed in a variety of cancers $(9,22-26)$. Some recent studies suggested that hnRNP A2/B1 is a proto-oncogene, especially in non-small cell lung cancer, the expression of hnRNP A2/B1 may be used as the reference index for evaluating the status and prognostic indicator of disease (27). The functional role of hnRNP A2/B1 in cervical cancer is rarely reported. Following previous reports, we used cervical cancer cell lines HeLa and CaSki cells with hnRNP A2/B1 knockdown by shRNA as a model to study the role of hnRNP A2/B1 in cervical cancer.

hnRNPA2/B1, as a new focus of cancer-associated tumor antigen has gradually attracted scientists' attention. A study by Sinha and colleague showed that hnRNP A2/B1 may be combined with the telomere repeated sequence TTAGGG to protect the telomere from destruction by ribozyme (28). To investigate how to interrupt these factors, receptor and oncogene signaling pathway to inhibit cancer cell proliferation, invasion and migration has become one of the main strategies for the development of new anticancer drugs. As before, hnRNP A2/B1 knockdown in this study suggested that the proliferation of cervical cancer cell lines was markedly decreased compared to the control group. The proliferation-related antigen PCNA and Ki-67 were also significantly reduced after hnRNP A2/B1 knockdown in vivo. According to previous studies, proliferation-related antigen $\mathrm{Ki}-67$ and proliferating cell nuclear antigen (PCNA) are proteins that are present in the cell proliferative phase and are one of the markers of proliferating cells (29). Similarly, our study also showed that hnRNP A2/B1 knockdown could inhibit cell colony formation. Upregulated proliferation of cancer cells is one of the mechanism of tumor growth and is the basis of the occurrence and development of cancer cells $(30,31)$.

Previous data reported that hnRNP A2/B1 plays an important role in the regulation of the migration, invasion and drug resistance in partial cancer cells. In addition, the process of therapy resistance during the development of pancreatic cancer is related to the high expession of hnRNPA2/B1 (32-35). This study showed that the inhibition of hnRNP A2/B1 in cervical cancer cell lines could decrease the ability of migration and invasion. After chemotherapy with lobaplatin and irinotecan respectively, the $\mathrm{IC}_{50}$ value was significantly reduced in hnRNP A2/B1 knockdown group, these results also confirmed previous research conclusions. This suggests that hnRNP A2/B1 in cervical cancer is associated with drug sensitivity and may be one of the mechanism in enhancement of therapy sensitivity by hnRNP A2/B1 knockdown.

Silencing hnRNP A2/B1 resulted in G1/S cell cycle arrest and accumulation of G0/G1 phase cells (36). The restriction point of cell cycle at G1/S transition is particularly important and determines the conversion of cell cycle time, the number of S phase and G2/M phase cell proportion can reflect the state of cell proliferation, suggesting active cell growth. The upregulation of checkpoint in cell cycle is closely related to the occurrence of tumors which induce cell apoptosis (37), and another study also suggested that hnRNP A2/B1 can regulate the expression of p14 and p16 and activate cyclin-dependent kinase 4 to assure the transition between G1 and S phase (38). The levels of $S$ phase and G2/M phase were decreased in hnRNP A2/B1 knockdown cervical cancer cells which demonstrated that silencing hnRNP A2/B1 could block cervical cancer cell cycle in G1 phase to prevent cell proliferation. Moreover, we indicated that hnRNP A2/B1 knockdown can induce cell apoptosis. p21 and p27, as the inhibitor of cyclin-dependent kinases (CDKs), plays an important part in regulation of cell cycle $(39,40)$. Just as our results, the expression of p21 and p27 were increased in vitro and vivo at hnRNP A2/B1 downregulation group and the result suggested that the hnRNP A2/B1 affected cell cycle by regulated p21 and p27 in cervical cancer. Previous studies showed that hnRNP A2/B1 can upregulate the proportion of anti-apoptosis factors and proteins in cells to promote the malignant growth of tumors (41), our study also confirmed this argument. Caspase- 3 may be involved in cell apoptosis (42), our results indicated that silencing hnRNP A2/B1 enhanced apoptosis in cervical cancer via activation of caspase-3.

Aberrant activation of the PI3K/AKT pathway is widespread in malignant tumors and is an important pathway to mediate cell cycle, and apoptosis $(43,44)$. Licochalcone A induced autophagy by inactivation of PI3K/AKT/mTOR pathway in cervical cancer cells (45). Activation of the PI3K/AKT pathway could reflect phosphorylation levels of AKT proteins and after phosphorylation, it could be further activated a variety of downstream proteins, such as $\mathrm{p} 21, \mathrm{p} 27$ and caspase-3, which could regulate the state of tumor cells. Our results demonstrated that the expression of p-AKT was reduced in hnRNP A2/B1 knockdown group both in vitro and in vivo and hnRNP A2/B1 was related to PI3K/AKT pathway in promotion of cervical cancer. Previous studies have reported that hnRNP A2/B1 regulates the self-renewal, cell cycle and pluripotency in human embryonic stem cells is related to PI3K/AKT pathway (46) and this was similar to our results.

In conclusion, our findings demonstrate that inhibiting hnRNP A2/B1 expression in cervical cancer can induce apoptosis and cell cycle arrest and enhance the chemotherapy sensitivity of cervical cancer cells to lobaplatin and irinotecan. 
Analysis of cervical cancer cell lines HeLa and CaSki cells in vitro shows that hnRNP A2/B1 knockdown can reduce the ability of cell proliferation, invation and migration, indicating that hnRNP A2/B1 may be one of the central regulators for cervical cancer. The activation of $\mathrm{PI} 3 \mathrm{~K} / \mathrm{AKT}$ pathway is one of the important mechanisms for hnRNP A2/B1 to facilitate the development of cervical cancer. Therefore, our study suggests that hnRNP A2/B1 may be an important molecular target for cancer treatment of cervical cancer and provide a new direction for clinical treatment of cervical cancer.

\section{Acknowledgements}

This study was supported by National Natural Science Foundation of China (2015-81560481) and The Joint Funds of Science and Technology Department of Guizhou Province and Affiliated Hospital of Guizhou Medical University (2015-7410).

\section{References}

1. Yoysungnoen B, Bhattarakosol P, Changtam C and Patumraj S: Effects of tetrahydrocurcumin on tumor growth and cellular signaling in cervical cancer xenografts in nude mice. Biomed Res Int 2016: 1781208, 2016.

2. Chen W, Zheng R, Zeng H, Zhang S and He J: Annual report on status of cancer in China, 2011. Chin J Cancer Res 27: 2-12, 2015

3. Lin WC, Kuo KL, Shi CS, Wu JT, Hsieh JT, Chang HC, Liao SM Chou CT, Chiang CK, Chiu WS, et al: MLN4924, a Novel NEDD8-activating enzyme inhibitor, exhibits antitumor activity and enhances cisplatin-induced cytotoxicity in human cervical carcinoma: In vitro and in vivo study. Am J Cancer Res 5: 3350-3362, 2015 .

4. Koh WJ, Greer BE, Abu-Rustum NR, Apte SM, Campos SM, Chan J, Cho KR, Cohn D, Crispens MA, DuPont N, et al: Cervical cancer. J Natl Compr Canc Netw 11: 320-343, 2013.

5. Ma X, Zhang J, Liu S, Huang Y, Chen B and Wang D: Nrf2 knockdown by shRNA inhibits tumor growth and increases efficacy of chemotherapy in cervical cancer. Cancer Chemother Pharmacol 69: 485-494, 2012.

6. Dreyfuss G, Kim VN and Kataoka N: Messenger-RNA-binding proteins and the messages they carry. Nat Rev Mol Cell Biol 3: 195-205, 2002

7. Kozu T, Henrich B and Schäfer KP: Structure and expression of the gene (HNRPA2B1) encoding the human hnRNP protein A2/B1. Genomics 25: 365-371, 1995.

8. He Y, Brown MA, Rothnagel JA, Saunders NA and Smith R: Roles of heterogeneous nuclear ribonucleoproteins A and B in cell proliferation. J Cell Sci 118: 3173-3183, 2005.

9. Patry C, Bouchard L, Labrecque P, Gendron D, Lemieux B, Toutant J, Lapointe E, Wellinger R and Chabot B: Small interfering RNA-mediated reduction in heterogeneous nuclear ribonucleoparticule A1/A2 proteins induces apoptosis in human cancer cells but not in normal mortal cell lines. Cancer Res 63 : 7679-7688, 2003.

10. Izaurralde E, Jarmolowski A, Beisel C, Mattaj IW, Dreyfuss G and Fischer U: A role for the M9 transport signal of hnRNP A1 in mRNA nuclear export. J Cell Biol 137: 27-35, 1997.

11. He Y and Smith R: Nuclear functions of heterogeneous nuclear ribonucleoproteins A/B. Cell Mol Life Sci 66: 1239-1256, 2009.

12. Kamma H, Horiguchi H, Wan L, Matsui M, Fujiwara M, Fujimoto M, Yazawa T and Dreyfuss G: Molecular characterization of the hnRNPA2/B1 proteins: Tissue-specific expression and novel isoforms. Exp Cell Res 246: 399-411, 1999.

13. Qu XH, Liu JL, Zhong XW, Li XI and Zhang QG: Insights into the roles of hnRNP A2/B1 and AXL in non-small cell lung cancer. Oncol Lett 10: 1677-1685, 2015.

14. Joshi J, Fernandez-Marcos PJ, Galvez A, Amanchy R, Linares JF, Duran A, Pathrose P, Leitges M, Cañamero M, Collado M, et al: Par-4 inhibits Akt and suppresses Ras-induced lung tumorigenesis. EMBO J 27: 2181-2193, 2008.

15. Zhang M, Fang X, Liu H, Guo R, Wu X, Li B, Zhu F, Ling Y, Griffith BN, Wang S and Yang D: Bioinformatics-based discovery and characterization of an AKT-selective inhibitor 9-chloro-2-methylellipticinium acetate (CMEP) in breast cancer cells. Cancer Lett 252: 244-258, 2007.
16. Gao N, Flynn DC, Zhang Z, Zhong XS, Walker V, Liu KJ, Shi X and Jiang BH: G1 cell cycle progression and the expression of G1 cyclins are regulated by PI3K/AKT/mTOR/P70S6KI signaling in human ovarian cancer cells. Am J Physiol Cell Physiol 287: C281-C291, 2004.

17. Polivka J Jr and Janku F: Molecular targets for cancer therapy in the PI3K/AKT/mTOR pathway. Pharmacol Ther 142: 164-175, 2014.

18. Li X, Ran L, Fang W and Wang D: Lobaplatin arrests cell cycle progression, induces apoptosis and alters the proteome in human cervical cancer cell line CaSki. Biomed Pharmacother 68: 291-297, 2014.

19. Jang HJ, Hong EM, Lee J, Choi JE, Park SW, Byun HW, Koh DH, Choi MH, Kae SH and Lee J: Synergistic effects of simvastatin and Irinotecan against colon cancer cells with or without Irinotecan resistance. Gastroenterol Res Pract 2016: 7891374, 2016.

20. Kodawara T, Higashi T, Negoro Y, Kamitani Y, Igarashi T, Watanabe K, Tsukamoto H, Yano R, Masada M, Iwasaki H and Nakamura T: The inhibitory effect of Ciprofloxacin on the $\beta$-Glucuronidase-mediated deconjugation of the Irinotecan metabolite SN-38-G. Basic Clin Pharmacol Toxicol 118: 333-337, 2016.

21. Ren C, Ren T, Yang K, Wang S, Bao X, Zhang F and Guo W: Inhibition of SOX2 induces cell apoptosis and G1/S arrest in Ewing's sarcoma through the PI3K/Akt pathway. J Exp Clin Cancer Res 35: 44, 2016.

22. Golan-Gerstl R, Cohen M, Shilo A, Suh SS, Bakàcs A, Coppola L and Karni R: Splicing factor hnRNPA2/B1 regulates tumor suppressor gene splicing and is an oncogenic driver in glioblastoma. Cancer Res 7: 4464-4472, 2011.

23. Shilo A, Ben Hur V, Denichenko P, Stein I, Pikarsky E, Rauch J, Kolch W, Zender L and Karni R: Splicing factor hnRNP A2 activates the Ras-MAPK-ERK pathway by controlling A-Raf splicing in hepatocellular carcinoma development. RNA 20: 505-515, 2014.

24. David CJ, Chen M, Assanah M, Canoll P and Manley JL: hnRNP proteins controlled by c-Myc deregulate pyruvate kinase mRNA splicing in cancer. Nature 463: 364-368, 2010.

25. Zhao CH, Li QF, Chen LY, Tang J, Song JY and Xie Z: Expression and localization of hnRNP A2/B1 during differentiation of human osteosarcoma MG-63 cells induced by HMBA. Ai Zheng 27: 677-684, 2008 (In Chinese).

26. Katsimpoula S, Patrinou-Georgoula M, Makrilia N, Dimakou K, Guialis A, Orfanidou D and Syrigos KN: Overexpression of hnRNPA2/B1 in bronchoscopic specimens: A potential early detection marker in lung cancer. Anticancer Res 29: 1373-1382, 2009.

27. Etcheverry GJ: 2006 Nobel prize in physiology or medicine. The silence of genes. Medicina (B Aires) 67: 92-95, 2007.

28. Sinha P, Poland J, Kohl S, Schnölzer M, Helmbach H, Hütter G, Lage $\mathrm{H}$ and Schadendorf D: Study of the development of chemoresistance in melanoma cell line using proteome analysis. Electrophoresis 24: 2386-2404, 2013.

29. Bologna-Molina R, Mosqueda-Taylor A, Molina-Frechero N, Mori-Estevez AD and Sánchez-Acuña G: Comparison of the value of PCNA and Ki67 as markers of cell proliferation in ameloblastic tumors. Med Oral Patol Oral Cir Bucal 18: e174-e179, 2013.

30. Cotrim P, Martelli-Junior H, Graner E, Sauk JJ and Coletta RD: Cyclosporin A induces proliferation in human gingival fibroblasts via induction of transforming growth factor-beta1. Periodontol 74: 1625-1633, 2003.

31. Stanley G, Harvey K, Slivova V, Jiang J and Sliva D: Ganoderma lucidum suppresses angiogenesis through the inhibition of secretion of VEGF and TGF-beta1 from prostate cancer cells. Biochem Biophys Res Commun 330: 46-52, 2005.

32. Clower CV,Chatterjee D, Wang Z, Cantley LC, Vander Heiden MG and Krainer AR: The alternative splicing repressors hnRNP $\mathrm{A} 1 / \mathrm{A} 2$ and PTB influence pyruvate kinase isoform expression and cell metabolism. Proc Nati Acad Sci USA 107: 1894-1899, 2010.

33. Gu WJ and Liu HL: Induction of pancreatic cancer cell apoptosis, invasion, migration, and enhancement of chemotherapy sensitivity of gemcitabine, 5-FU, and oxaliplatin by hnRNP A2/B1 siRNA. Anticancer Drugs 24: 566-576, 2013.

34. Tauler J, Zudaire E, Liu H, Shih J and Mulshine JL: hnRNP A2/B1 modulates epithelial-mesenchymal transition in lung cancer cell lines. Cancer Res 70: 7137-7147, 2010. 
35. Wang L, Liu HL, Li Y and Yuan P: Proteomic analysis of pancreatic intraepithelial neoplasia and pancreatic carcinoma in rat models. World J Gastroenterol 17: 1434-1441, 2011.

36. Hallett RM, Huang C, Motazedian A, Auf der Mauer S, Pond GR Hassell JA, Nordon RE and Draper JS: Treatment-induced cell cycle kinetics dictate tumor response to chemotherapy. Oncotarget 6: 7040-7052, 2015.

37. Montague JW and Cidlowski JA: Cellular catabolism in apoptosis: DNA degradation and end nuclease activation. Experientia 52: 857-862, 1996.

38. Zhu D, Xu G, Ghandhi S and Hubbard K: Modulation of the expression of p16INK4a and p14AKT by hnRNPA1 and A2 RNA binding proteins: Implications for cellular senescence. J Cell Physiol 193: 19-25, 2002.

39. Chu I, Sun J, Arnaout A, Kahn H, Hanna W, Narod S, Sun P, Tan CK, Hengst L and Slingerland J: p27 phosphorylation by Src regulates inhibition of cyclin E-Cdk2. Cell 128: 281-294, 2007.

40. Gartel AL and Radhakrishnan SK: Lost in transcription: p21 repression, mechanisms and consequences. Cancer Res 65: 3980-3985, 2005.

41. Chen ZY, Cai L, Zhu J, Chen M, Chen J, Li ZH, Liu XD, Wang SG, Bie P, Jiang P, et al: Fyn requires hnRNPA2/B1 and Sam68 to synergistically regulate apoptosis in pancreatic cancer. Carcinogenesis 32: 1419-1426, 2011
42. Zimmermann KC, Bonzon $\mathrm{C}$ and Green DR: The machinery of programmed cell death. Pharmacol Ther 92: 57-70, 2001.

43. Stegeman H, Span PN, Kaanders JH and Bussink J: Improving chemoradiation efficacy by PI3-K/AKT inhibition. Cancer Treat Rev 40: 1182-1191, 2014.

44. Manning BD and Cantley LC: AKT/PKB Signaling: Navigating downstream. Cell 129: 1261-1274, 2007.

45. Tsai JP, Lee CH, Ying TH, Lin CL, Hsueh JT and Hsieh YH: Licochalcone A induces autophagy through $\mathrm{PI} 3 \mathrm{~K} / \mathrm{Akt} / \mathrm{mTOR}$ inactivation and autophagy suppression enhances Licochalcone A-induced apoptosis of human cervical cancer cells. Oncotarget 6: 28851-28866, 2015.

46. Choi HS, Lee HM, Jang YJ, Kim CH and Ryu CJ: Heterogeneous nuclear ribonucleoprotein A2/B1 regulates the self-renewal and pluripotency of human embryonic stem cells via the control of the G1/S transition. Stem Cells 31: 2647-2658, 2013.

This work is licensed under a Creative Commons Attribution-NonCommercial-NoDerivatives 4.0 International (CC BY-NC-ND 4.0) License. 